Vliet, L.M. van, Veer, A.J.E. de, Raijmakers, N.J.H., Francke, A.L. Is information provision about benefits and risks of treatment options associated with receiving person-centered care: a survey among incurably ill cancer patients. Journal of Palliative Medicine: 2019, 7, p. 797-803

Postprint version

Journal website

: $\quad$ https://www.liebertpub.com/doi/full/10.1089/jpm.2018.0591

Pubmed link

DOI

: $\quad$ https://www.ncbi.nlm.nih.gov/pubmed/30676846

: $10.1089 / j p m .2018 .0591$

This is a Nivel certified Post Print, more info at nivel.nl

\title{
Is Information Provision About Benefits and Risks of Treatment Options Associated with Receiving Person-Centered Care: A Survey among Incurably III Cancer Patients
}

\author{
Liesbeth M. van Vliet, PhD, ${ }^{1}$ Anke J.E. de Veer, PhD, ${ }^{1}$ Natasja J.H. \\ Raijmakers, PhD, ${ }^{1,2}$ and Anneke Francke, $\mathrm{PhD}^{1,3}$
}

1Nivel, Netherlands Institute of Health Services Research, Utrecht, the Netherlands. 2Netherlands Comprehensive Cancer Organization (IKNL), Utrecht, the Netherlands. 3Department of Public and Occupational Health, Amsterdam UMC, Vrije Universiteit Amsterdam, Amsterdam Public Health Research Institute, Amsterdam, the Netherlands.

\section{Abstract}

Background: Cancer patients with advanced disease are confronted with increasingly complex life-prolonging/symptom-relieving treatment decisions. Being informed of treatment benefits and risks is important, but information provision might be suboptimal.

Objective: To assess the extent to which patients with incurable cancer feel informed about benefits and risks of possible treatments, and whether this relates to their selfperceived receipt of person-centered care.

Methods: Patients with incurable cancer $(N=212)$ reported the degree to which they felt informed about treatment benefits/risks. Person-centered care was operationalized as "feeling involved in care" and "feeling that preferences were taken into account". (Logistic) regression analyses assessed the relationship between feeling informed and receiving person-centered care, exploring moderating influences of background characteristics.

Results: Two-thirds (66\%) of patients felt incompletely informed about treatment benefits/risks. Two-thirds (65\%) of patients felt that they were always involved in their care, and $60 \%$ felt their preferences were taken into account by all providers. If patients felt completely informed, they also felt they received more person-centered care $(p=<$ 0.01). Seventy six percent and $81 \%$ of completely informed versus $58 \%$ and $50 \%$ of incompletely informed patients felt that they were, respectively, always involved and that preferences were taken into account by all providers. Background characteristics did 
Vliet, L.M. van, Veer, A.J.E. de, Raijmakers, N.J.H., Francke, A.L. Is information provision about benefits and risks of treatment options associated with receiving person-centered care: a survey among incurably ill cancer patients. Journal of Palliative Medicine: 2019, 7, p. 797-803

not moderate these relationships, but influenced perceptions of received information and person-centered care.

Conclusions: Complete information provision about treatment benefits and risks is, according to patients, not commonplace. Yet such information is related to receiving person-centered care. More research into what specific information is preferred, provided, and remembered is warranted, to achieve optimal person-centered care.

\section{Introduction}

Cancer patients are confronted with increasingly complex treatment options and decisions, also in the extending phase of a life-limiting disease..$^{1,2}$ Treatments may focus either on life prolongation, accepting the risk of adverse effects, or on symptom relief (palliation). Being informed of potential positive and detrimental treatment consequences is important in advanced illness, where treatment decisions are made in a context of limited time and prevalent symptom burden. ${ }^{3,4}$

While there is evidence that incurably ill cancer patients are not always aware of and informed of treatment benefits and risks, patient's own perception of the extent to which they feel informed is still unexplored. For example, it is common for patients to hold unrealistic and sometimes inconsistent

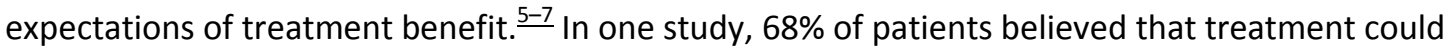
erase their cancer, but only $55 \%$ believed their disease was curable, indicating that even patients with accurate disease insight might hold inaccurate beliefs about treatment benefits. $\underline{6}$ A lack of open communication from clinicians might contribute to these findings. Observational studies have found a lack of open communication about aims, options, and side effects of treatments in advanced illness.

$\underline{10}$ However, insight into the extent to which people with incurable cancers themselves feel informed about potential benefits and risks of treatment options is largely missing.

It is moreover unclear whether patients who feel better informed about treatment benefits and risks also experience their care as more person centered, that is, that care is respectful of and responsive to


quality palliative care. ${ }^{12}, \underline{13}$ Focusing on terminal care, there is evidence that early discussion of end-oflife care preferences can result in receipt of terminal care more aligned to patients' preferences. $\frac{14}{}$ This is an important finding, as patients' often continue to receive anticancer treatment when their disease progresses $\frac{15-18}{}$ increasing the risk of negative outcomes such as (emergency) hospital admissions, $\frac{16}{}$ intensive medical interventions at the end of life, $\stackrel{17}{ }$ and impaired quality of death. $\underline{17} \underline{19}$ Greater insight into whether information provision about potential benefits and risks of treatments is associated with patients' perception of receiving person-centered care preceding the terminal phase is vital.

Therefore this study had two aims: first, to determine the extent to which incurably ill cancer patients feel that they have been informed about the benefits and risks of treatment options. Second, to determine the relationship between feeling informed and patient perception of having received person-centered care.

\section{Methods}

\section{Study design}

Cross-sectional analysis of an existing set of questionnaire data, obtained in the evaluation study of the Dutch National Quality Improvement Program for Palliative Care (2012-2016). $\stackrel{20}{\text { The Evaluation }}$ Program was assessed and approved by the Ethics Committee of the University Medical Center in Leiden, the Netherlands (P13.03/NV/nv).

\section{Participants}

The patient inclusion criteria for the evaluation study were as follows: life expectancy $<6$ months (assessed by the surprise question ${ }^{21}$ ) and/or who underwent palliative treatment, understood Dutch, 
Vliet, L.M. van, Veer, A.J.E. de, Raijmakers, N.J.H., Francke, A.L. Is information provision about benefits and risks of treatment options associated with receiving person-centered care: a survey among incurably ill cancer patients. Journal of Palliative Medicine: 2019, 7, p. 797-803

were physically and mentally capable to respond to questionnaires, and had a $>1$ week care relationship. Health care professionals participating in the Evaluation Program collected contact details of patients meeting these criteria over a one month period. Patients received a questionnaire by post; data were collected from institutionalized patients through an interview. For this analysis only data from cancer patients were included $(N=212)$.

\section{Measures}

Several items of the validated questionnaire Consumer Quality Index Palliative care (patient version) ${ }^{22}$ were analyzed for this article.

\section{Received information}

The degree to which patients felt that they had received information about benefits and risks/side effects of different treatment options was assessed (answer categories "no, not at all", "a bit", "mostly", "yes completely").

\section{Receipt of person-centered care}

The degree to which patients felt that they had received person-centered care was assessed with two items, assessing the extent to which patients felt:

(i) Involved in decisions about the care they received (answer categories: "never", "sometimes", "most of the time", "always")

(ii) Care providers took their personal preferences/wishes into account (answer categories: "none", "some", "most", "all").

Background characteristics that may influence communication preferences or experiences in advanced

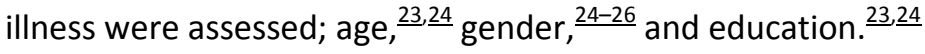

\section{Statistical analysis}

Analysis was conducted in four stages. First, descriptive statistics was used to assess whether patients felt they had received information (dichotomizing answer options into "completely" ["yes completely"] and "incompletely" ["no, not at all", "a bit", and "mostly"]) and felt they had received person-centered care. Second, (logistic) regression analyses determined the influence of background characteristics (age, gender, and education) on whether patients felt completely informed and felt they had received person-centered care. Third, regression analyses assessed the relationship between feeling informed (completely/incompletely) and receiving person-centered care. A sensitivity analysis was performed, using logistic regression with alternative dichotomization of the responses into "completely" ("yes completely" and "mostly") and "incompletely" ("no, not at all" and "a bit")

Fourth, the moderating effects of background characteristics found to be significant in step 2 on the relationship between feeling informed and receiving person-centered care were assessed. Interaction effects between background characteristics and feeling informed (completely/incompletely) were created, and regression analyses were performed. All analyses were conducted using Stata 14 with two-sided significance testing at $p \leq 0.05$. Missing data were not imputed.

\section{Results}

Background characteristics of patients are shown in Table 1. 
Vliet, L.M. van, Veer, A.J.E. de, Raijmakers, N.J.H., Francke, A.L. Is information provision about benefits and risks of treatment options associated with receiving person-centered care: a survey among incurably ill cancer patients. Journal of Palliative Medicine: 2019, 7, p. 797-803

\section{[table 1]}

\section{Feeling informed}

One-third (33\%) of patients felt completely informed about benefits and risks/side effects of available treatment options, $38 \%$ felt mostly informed, $14 \%$ felt a bit informed, and $14 \%$ felt not informed at all (Table 2).

Female ( $p=0.07 ; \mathrm{OR}=0.57,95 \% \mathrm{Cl}: 0.31-1.04$, tendency) and higher educated $(p=0.03 ; \mathrm{OR}=0.70$, $95 \% \mathrm{Cl}: 0.51-0.96)$ patients felt less completely informed (Fig. 1). Age did not influence the perception of feeling completely informed ( $p=0.14 ; \beta=-0.02,95 \% \mathrm{Cl}:-0.04$ to 0.01$)$.

\section{[figure 1][figure 2]}

\section{Person-centered care}

Two-thirds (65\%) of patients felt that they were always involved in the care they received, $28 \%$ most of the time, $5 \%$ sometimes, and $1 \%$ felt that they were never involved (Table 2). Higher educated patients tended to feel less involved $(p=0.08 ; \beta=-0.08,95 \% \mathrm{Cl}:-0.17$ to 0.01$)$. Neither gender ( $p=0.71 ; \beta=-0.04,95 \% \mathrm{Cl}:-0.22$ to 0.15$)$ nor age $(p=0.15 ; \beta=-0.01,95 \% \mathrm{Cl}$ : -0.01 to 0.00$)$ influenced perceived involvement in care received (gender and education displayed in Fig. 2). Sixty percent of patients felt that their personal preferences were taken into account by all providers, $32 \%$ by most, $8 \%$ by some (Table 2 ). Older patients tended to feel that their preferences were taken less into account $(p=0.08 ; \beta=-0.01,95 \% \mathrm{Cl}:-0.01$ to 0.00 , tendency). Neither gender $(p=0.31$; $\beta=-0.09,95 \% \mathrm{Cl}:-0.27$ to 0.09 ), nor education ( $p=0.17 ; \beta=-0.06,95 \% \mathrm{Cl}:-0.15$ to 0.03 ) influenced the perception that personal preferences were taken into account (gender and education displayed in Fig. 3).

\section{[figure 3][figure 4]}

\section{Association between feeling informed and receiving person-centered care}

Patients who felt completely informed about treatment benefits and risks also felt more involved in their care $(p=0.01 ; \beta=0.29,95 \% \mathrm{Cl}: 0.08-0.49)$ and that their preferences were taken into account $(p<0.01 ; \beta=0.42,95 \% \mathrm{Cl}: 0.23-0.60)$. More specifically, as illustrated in Figure $4 \mathrm{a}$ and $\mathrm{b}, 76 \%$ of the patients who felt completely informed also felt that they were always involved in their care, compared to $58 \%$ of patients who felt incompletely informed. Moreover, $81 \%$ of patients who felt completely informed stated that their preferences were taken into account by all providers, compared to $50 \%$ of the patients who felt incompletely informed.

The sensitivity analysis found that the relationship between feeling informed and feeling involved in care $(p<0.01 ; \beta=0.36,95 \% \mathrm{Cl}: 0.15-0.57)$ and feeling that preferences were taken into account $(p<0.01 ; \beta=0.45,95 \% \mathrm{Cl}: 0.26-0.65)$ remained significant, when an alternative dichotomization of the variables was used.

\section{Moderating effects of background characteristics}

The moderating effect of education on the relationship between feeling informed and feeling involved was insignificant ( $p=0.34 ; \beta=0.10,95 \% \mathrm{Cl}:-0.10$ to 0.30 ). The moderating effect of age on the relationship between feeling informed and feeling that preferences were taken into account was also insignificant ( $p=0.24 ; \beta=-0.01,95 \% \mathrm{Cl}:-0.02$ to 0.01 ). 
Vliet, L.M. van, Veer, A.J.E. de, Raijmakers, N.J.H., Francke, A.L. Is information provision about benefits and risks of treatment options associated with receiving person-centered care: a survey among incurably ill cancer patients. Journal of Palliative Medicine: 2019, 7, p. 797-803

\section{Discussion}

In this survey of Dutch cancer patients with advanced disease, two-thirds of patients felt incompletely informed about treatment benefits and risks. When patients did feel completely informed, they also felt more involved in their received care and that their preferences were better taken into account. Our study adds to the evidence that open communication in advanced cancer is not always achieved, even though it is increasingly recognized as important. ${ }^{27}$ Most patients in our study felt incompletely informed about treatment benefits and risks. This corroborates observational studies which found that information about an illness being incurable is not mentioned or mentioned only briefly in $47 \%$ of consultations, while side effect information is omitted in $22-93 \%$ of consultations ${ }^{-}$(depending on specific side effect). When treatment information is discussed, this is mostly done in general terms. .9 Previous Dutch studies found that incurably ill (cancer) patients perceive the provision of information about treatment benefits and risks as important $\frac{28}{}$ and in need of improvement. $\stackrel{22}{\text { Moreover, }} 95 \%$ of advanced cancer patients in a recent study opted to receive information about possible adverse

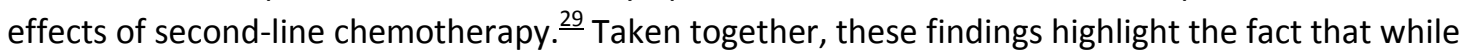
most patients want to be extensively informed about benefits and risks of treatment, this seems not consistently done and is not being experienced as such.

This is problematic, given our finding that being well-informed is associated with perceived receipt of person-centered care. Our results provide further evidence for the link between improved communication and improved patient outcomes $\underline{\underline{14}, \underline{19}}$ and support recent ASCO guidance stressing the importance of discussing treatment benefits and risks. ${ }^{27}$ Being well-informed is a prerequisite for making well-informed treatment decisions. ${ }^{30}$ Seriously ill patients who hold unrealistic beliefs about treatment benefit, for example, who are convinced chemotherapy will prolong life ${ }^{31}$ or face a $1 \%$ chance for cure, $\underline{\underline{32}}$ may be inclined to accept all side effects. It should be noted that in this study, we did not assess the specific decisions that were being made. However, in the advanced phase of a disease, care plans are appropriate if consistent with patient preferences. ${ }^{12}$ To achieve care that takes preferences into account, appropriate information provision about treatment benefits and risks (if preferred by patients) seems crucial.

While the positive association between feeling informed and perceived receipt of person-centered care was evident for all patients, background characteristics did influence feelings of received information and care. Higher educated ${ }^{23,24}$ and female ${ }^{24}$ patients tend to have high information needs, explaining our findings that they were less likely to feel completely informed. The communication barriers which older patients can experience due to functional and cognitive decline and multimorbidity ${ }^{33}$ might contribute to the finding that fewer older people perceived that their preferences had been taken into account by all.

These results beg the question how can clinicians best inform patients about treatment benefits and risks, to achieve optimal person-centered care? Although we did not assess which information was conveyed or preferred-and information preferences vary between patients $\underline{23,34,35}$ - the importance of lay language, discussing potential adverse effects, acknowledging uncertainty, and checking patients' understanding has been highlighted..$^{27,36}$ Information should be tailored to patients' changing preferences,,$\underline{23}$ and this can be achieved by asking patients about their preferences ${ }^{37}$ instead of making potentially incorrect assumptions. ${ }^{29}, \underline{38}, \underline{39}$ While providing information is important, the risks of information provision should also be acknowledged. If patients are informed of ${ }^{40}$ or expect side effects to arise, ${ }^{41,42}$ this increases their occurrence. ${ }^{43}$ The optimal balance between full information disclosure without increasing the risk of side effects remains to be determined.

This study has strengths; we used data from a nationwide, relatively large sample of people with incurable cancer. It also has limitations. First, we did not know what specific information was provided to patients, as consultations were not recorded. Our findings might underestimate what was discussed, as patients' information recall is often impaired $\frac{44-47}{}$; only $40-50 \%$ of treatment related information was recalled in one (experimental) study of advanced cancer consultations. ${ }^{44}$ We believe, 
Vliet, L.M. van, Veer, A.J.E. de, Raijmakers, N.J.H., Francke, A.L. Is information provision about benefits and risks of treatment options associated with receiving person-centered care: a survey among incurably ill cancer patients. Journal of Palliative Medicine: 2019, 7, p. 797-803

however, that what patients remember, opposed to what is provided, has ultimately most clinical relevance and that assessing patients' perceptions is a strength of the study. Second, we used a single question to determine whether patients felt informed about both benefits and risks. Previous studies found that $65-70 \%$ of incurable ill cancer patients felt informed about risks $\underline{48,49}$ indicating a potential lack in discussing benefits. Third, due to the survey design we can infer relationships, but cannot establish causality. Last, it is difficult to establish whether our sample is representative of those with advanced cancer in the Netherlands. Participation in the Quality Improvement Program might have led to positive perceptions of receiving person-centered care.

Future studies should consider the relationship between preferred, discussed, and recalled information in more detail using both audio-recordings of consultations and patient-reported recall of information, $\frac{46}{-}$ next to patients' stated preferences. This may provide more guidance for clinicians as to which information to provide and how best to do so to optimize patient recall. Further investigation of the relationship between the information provided about treatments and the treatment decisions that are made is also warranted. Observational studies of consultations can shed light on these questions. Moreover, the extent to which incurably ill patients are prone to experience side effects after being informed of them needs to be studied, to develop understanding of the balance between full information provision while not increasing the occurrence of side effects.

In conclusion, our results highlight that it is uncommon for patients with advanced cancer to feel that they have been fully informed about treatment benefits and risks. When patients feel fully informed, this is associated with perceived receipt of person-centered care. In our current era, the growing group of patients with advanced cancer is confronted with increasingly complex medical options. It is therefore essential that, tailored, information is provided, to support patients in planning for their future and making difficult treatment decisions affecting their quality and quantity of life.

\section{Acknowledgments}

The authors thank participants for completing the questionnaire. The authors thank Peter Spreeuwenberg for statistical advice. The authors thank Jolien Hofstede for her involvement in the Evaluation Program. The authors thank Simon Etkind for his advice on English grammer and style. The evaluation of the Dutch National Quality Improvement Program for Palliative Care was funded by ZonMw (844003002).

L.V. is funded by a Young Investigator Grant of the Dutch Cancer Society (10392). Both funders played no role in the design of the study, data collection, analysis, interpretation, in writing the article, or in the decision to submit the article for publication.

\section{Author Disclosure Statement}

No competing financial interests exist.

\section{References}

1. Cronin KA, Lake AJ, Scott S: Annual Report to the Nation on the Status of Cancer, part I: National cancer statistics. Cancer 2018;124:2785-2800.

2. Jemal A, Ward EM, Johnson CJ, et al.: Annual Report to the Nation on the Status of Cancer, 19752014, Featuring Survival. J Natl Cancer Inst 2017;109.

3. Ramsenthaler C, Kane $P$, Gao W, et al.: Prevalence of symptoms in patients with multiple myeloma: A systematic review and meta-analysis. Eur J Haematol 2016;97:416-429.

4. Teunissen SC, Wesker W, Kruitwagen C, et al.: Symptom prevalence in patients with incurable cancer: A systematic review. J Pain Symptom Manage 2007;34:94-104.

5. Weeks JC, Catalano PJ, Cronin A, et al.: Patients' expectations about effects of chemotherapy for advanced cancer. N Engl J Med 2012;367:1616-1625. 
Vliet, L.M. van, Veer, A.J.E. de, Raijmakers, N.J.H., Francke, A.L. Is information provision about benefits and risks of treatment options associated with receiving person-centered care: a survey among incurably ill cancer patients. Journal of Palliative Medicine: 2019, 7, p. 797-803

6. Yennurajalingam S, Rodrigues LF, Shamieh O, et al.: Perception of Curability Among Advanced Cancer Patients: An International Collaborative Study. Oncologist 2018;23: 501-506.

7. Chen $A B$, Cronin A, Weeks JC, et al.: Expectations about the effectiveness of radiation therapy among patients with incurable lung cancer. J Clin Oncol 2013;31:2730-2735.

8. Koedoot N, Molenaar S, Oosterveld P, et al.: The decisional conflict scale: Further validation in two samples of Dutch oncology patients. Patient Educ Couns 2001;45:187-193.

9. Brom L, De Snoo-Trimp JC, Onwuteaka-Philipsen BD, et al.: Challenges in shared decision making in advanced cancer care: A qualitative longitudinal observational and interview study. Health Expect 2017;20:69-84.

10. Gattellari M, Voigt KJ, Butow PN, Tattersall MH: When the treatment goal is not cure: Are cancer patients equipped to make informed decisions? J Clin Oncol 2002;20:503-513.

11. Institute of Medicine Committee on Quality of Health Care in A: Crossing the Quality Chasm: A New Health System for the 21st Century. Washington, DC: National Academies Press, 2001.

12. National Consensus Project for Quality Palliative Care: Clinical Practice Guidelines for Quality Palliative Care. Pittsburgh, PA: National Coalition for Hospice and Palliative Care, 2013.

13. Institute of Medicine: Dying in America: Improving Quality and Honoring Individual Preferences Near the End of Life. Washington, DC: The National Academies Press, 2015.

14. Mack JW, Weeks JC, Wright AA, et al.: End-of-life discussions, goal attainment, and distress at the end of life: Predictors and outcomes of receipt of care consistent with preferences. J Clin Oncol 2010;28:1203-1208.

15. Morden NE, Chang CH, Jacobson JO, et al.: End-of-life care for Medicare beneficiaries with cancer is highly intensive overall and varies widely. Health Aff 2012;31:786-796.

16. Bao Y, Maciejewski RC, Garrido MM, et al.: Chemotherapy Use, End-of-Life care, and costs of care among patients diagnosed with stage IV pancreatic cancer. J Pain Symptom Manage 2018;55:11131121.e1113.

17. Wright AA, Zhang B, Keating NL, et al.: Associations between palliative chemotherapy and adult cancer patients' end of life care and place of death: Prospective Cohort Study. BMJ 2014;348:g1219. 18. Ersek M, Miller SC, Wagner TH, et al.: Association between aggressive care and bereaved families' evaluation of end-of-life care for veterans with non-small cell lung cancer who died in Veterans Affairs facilities. Cancer 2017; 123:3186-3194.

19. Wright AA, Zhang B, Ray A, et al.: Associations between end-of-life discussions, patient mental health, medical care near death, and caregiver bereavement adjustment. JAMA 2008;300:1665-1673. 20. Raijmakers NJ, Hofstede JM, de Nijs EJ, et al.: The effect and process evaluations of the national quality improvement programme for palliative care: The study protocol. BMC Palliat Care 2014;13:5. 21. Murray S, Boyd K: Using the 'surprise question' can identify people with advanced heart failure and COPD who would benefit from a palliative care approach. Palliat Med 2011;25:382.

22. Claessen SJ, Francke AL, Sixma HJ, et al.: Measuring patients' experiences with palliative care: The Consumer Quality Index Palliative Care. BMJ Support Palliat Care 2012;2:367-372.

23. Parker SM, Clayton JM, Hancock K, et al.: A systematic review of prognostic/end-of-life communication with adults in the advanced stages of a life-limiting illness: Patient/ caregiver preferences for the content, style, and timing of information. J Pain Symptom Manage 2007;34:81-93. 24. Fujimori M, Uchitomi Y: Preferences of cancer patients regarding communication of bad news: A systematic literature review. Jpn J Clin Oncol 2009;39:201-216.

25. Sharma RK, Prigerson HG, Penedo FJ, Maciejewski PK: Male-female patient differences in the association between end-of-life discussions and receipt of intensive care near death. Cancer 2015;121:2814-2820.

26. Fletcher K, Prigerson HG, Paulk E, et al.: Gender differences in the evolution of illness understanding among patients with advanced cancer. J Support Oncol 2013;11:126-132.

27. Gilligan T, Coyle N, Frankel RM, et al.: Patient-Clinician Communication: American Society of Clinical Oncology Consensus Guideline. J Clin Oncol 2017;35:3618-3632. 
Vliet, L.M. van, Veer, A.J.E. de, Raijmakers, N.J.H., Francke, A.L. Is information provision about benefits and risks of treatment options associated with receiving person-centered care: a survey among incurably ill cancer patients. Journal of Palliative Medicine: 2019, 7, p. 797-803

28. Heins $M$, Hofstede J, Rijken M, et al.: Palliative care for patients with cancer: Do patients receive the care they consider important? A survey study. BMC Palliat Care 2018;17:61.

29. Oostendorp LJ, Ottevanger PB, van de Wouw AJ, et al.: Patients' preferences for information about the benefits and risks of second-line palliative chemotherapy and their oncologist's awareness of these preferences. J Cancer Educ 2016;31:443-448.

30. Elwyn G, Frosch D, Thomson R, et al.: Shared decision making: A model for clinical practice. J Gen Intern Med 2012;27:1361-1367.

31. Bergqvist J, Strang P: The will to live - breast cancer patients perceptions' of palliative chemotherapy. Acta Oncol 2017;56:1168-1174.

32. Slevin ML, Stubbs L, Plant HJ, et al.: Attitudes to chemotherapy: Comparing views of patients with cancer with those of doctors, nurses, and general public. BMJ 1990;300:1458-1460.

33. van Vliet LM, Lindenberger $E$, van Weert JC: Communication with older, seriously ill patients. Clin Geriatr Med 2015;31:219-230.

34. Leydon GM, Boulton M, Moynihan C, et al.: Cancer patients' information needs and information seeking behaviour: In depth interview study. BMJ 2000;320:909-913.

35. Innes S, Payne S: Advanced cancer patients' prognostic information preferences: A review. PalliatMed 2009;23:29-39.

36. Rodin G, Zimmermann C, Mayer C, et al.: Clinician-patient communication: Evidence-based recommendations to guide practice in cancer. Curr Oncol 2009;16:42-49.

37. van Vliet L, Francke A, Tomson S, et al.: When cure is no option: How explicit and hopeful can information be given? A qualitative study in breast cancer. Patient Educ Couns 2013;90:315-322.

38. Elkin EB, Kim SH, Casper ES, et al.: Desire for information and involvement in treatment decisions: Elderly cancer patients' preferences and their physicians' perceptions. J Clin Oncol 2007;25:52755280.

39. Bruera E, Sweeney C, Calder K, et al.: Patient preferences versus physician perceptions of treatment decisions in cancer care. J Clin Oncol 2001;19:2883-2885.

40. Amanzio M, Corazzini LL, Vase L, Benedetti F: A systematic review of adverse events in placebo groups of antimigraine clinical trials. Pain 2009;146:261-269.

41. Nestoriuc Y, von Blanckenburg P, Schuricht F, et al.: Is it best to expect the worst? Influence of patients' side-effect expectations on endocrine treatment outcome in a 2-year prospective clinical cohort study. Ann Oncol 2016;27: 1909-1915.

42. Devlin EJ, Denson LA, Whitford HS: Cancer treatment side effects: A Meta-analysis of the relationship between response expectancies and experience. J Pain Symptom Manage 2017;54:245258.e242.

43. Barsky AJ, Saintfort R, Rogers MP, Borus JF: Nonspecific medication side effects and the nocebo phenomenon. JAMA 2002;287:622-627.

44. van Osch M, Sep M, van Vliet LM, et al.: Reducing patients' anxiety and uncertainty, and improving recall in bad news consultations. Health Psychol 2014;33:1382-1390.

45. Sep MS, van Osch M, van Vliet LM, et al.: The power of clinicians' affective communication: How reassurance about non-abandonment can reduce patients' physiological arousal and increase information recall in bad news consultations. An experimental study using analogue patients. Patient Educ Couns 2014;95:45-52.

46. Jansen J, Butow PN, van Weert JC, et al.: Does age really matter? Recall of information presented to newly referred patients with cancer. J Clin Oncol 2008;26:5450-5457.

47. Friis LS, Elverdam B, Schmidt KG: The patient's perspective: A qualitative study of acute myeloid leukaemia patients' need for information and their informationseeking behaviour. Support Care Cancer 2003;11:162-170.

48. Husson $\mathrm{O}$, Thong MS, Mols F, et al.: Information provision and patient reported outcomes in patients with metastasized colorectal cancer: Results from the PROFILES registry. J Palliat Med 2013;16:281-288. 
Vliet, L.M. van, Veer, A.J.E. de, Raijmakers, N.J.H., Francke, A.L. Is information provision about benefits and risks of treatment options associated with receiving person-centered care: a survey among incurably ill cancer patients. Journal of Palliative Medicine: 2019, 7, p. 797-803

49. Voogt E, van Leeuwen AF, Visser AP, et al.: Information needs of patients with incurable cancer. Support Care Cancer 2005;13:943-948.

Tables

\begin{tabular}{||l|l|}
\hline \multicolumn{2}{|l|}{ Table 1. Background Characteristics } \\
\hline \hline & $M$ (range) N=191 \\
\hline \hline Age & $75(20-98)$ \\
\hline \hline & $N(\%)$ \\
\hline \hline Gender & $N=212$ \\
\hline \hline Male & $92(43)$ \\
\hline \hline Female & $120(57)$ \\
\hline Highest education & $N=202$ \\
\hline \hline Low (primary education or less) & $49(24)$ \\
\hline \hline Intermediate-1 (lower secondary) & $83(41)$ \\
\hline \hline Intermediate-2 (upper secondary) & $34(17)$ \\
\hline \hline High (tertiary) & $36(18)$ \\
\hline
\end{tabular}

From the 212 included participants, not all completed all measures. Hence, the number of participants per characteristic varies.

Table 2. Patient Experiences of Feeling Informed and Receiving Person-Centered Care (i.e., Involved in Care Received and Preferences Taken into Account)

\begin{tabular}{|c|c|c|c|c|c|}
\hline \multirow{2}{*}{\multicolumn{2}{|c|}{$\begin{array}{l}\text { Informed about benefits and risks/side } \\
\text { effects of treatment options }(\mathrm{N}=159)\end{array}$}} & \multicolumn{4}{|c|}{ Receiving person-centered care } \\
\hline & & \multicolumn{2}{|c|}{$\begin{array}{l}\text { Involved in care received } \\
(\mathrm{N}=205)\end{array}$} & \multicolumn{2}{|c|}{$\begin{array}{l}\text { Personal preferences taken } \\
\text { into account }(\mathrm{N}=205)\end{array}$} \\
\hline Answer option & $N(\%)$ & Answer option & $N(\%)$ & Answer option & $N(\%)$ \\
\hline Not at all (no) & $28(14)$ & Never & $3(1)$ & None & - \\
\hline A bit (no) & $27(14)$ & Sometimes & $11(5)$ & Some & $16(8)$ \\
\hline Mostly (no) & $75(38)$ & Most of the time & $58(28)$ & Most & $65(32)$ \\
\hline Completely (yes) & $65(33)$ & Always & $133(65)$ & ||All & $124(60)$ \\
\hline
\end{tabular}

From the 212 included participants, not all completed all measures. Hence, the number of participants per item varies.

Due to rounding, not all percentages add up to 100. 
Vliet, L.M. van, Veer, A.J.E. de, Raijmakers, N.J.H., Francke, A.L. Is information provision about benefits and risks of treatment options associated with receiving person-centered care: a survey among incurably ill cancer patients. Journal of Palliative Medicine: 2019, 7, p. 797-803

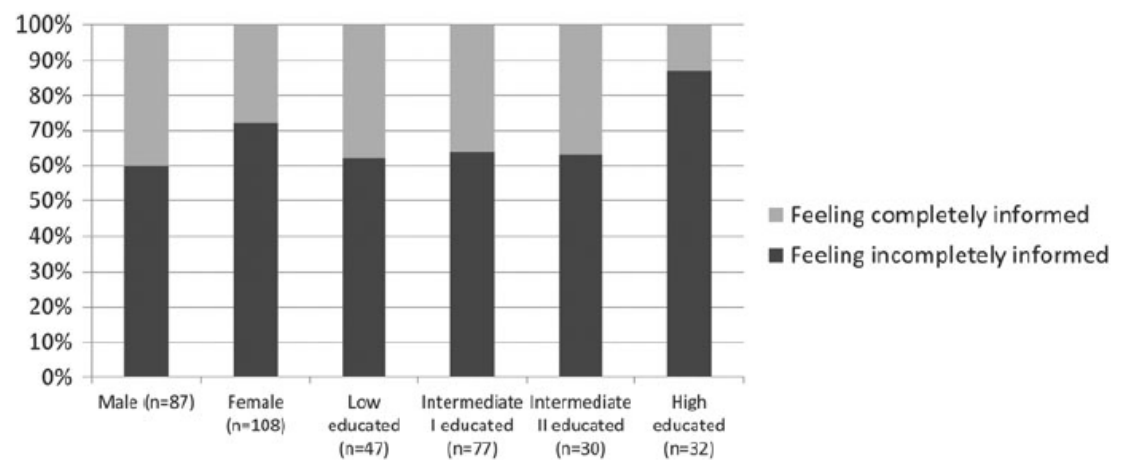

FIG. 1. Association between gender/education and feeling informed. From the 212 included participants, not all completed all measures. Hence, the number of participants per association varies.

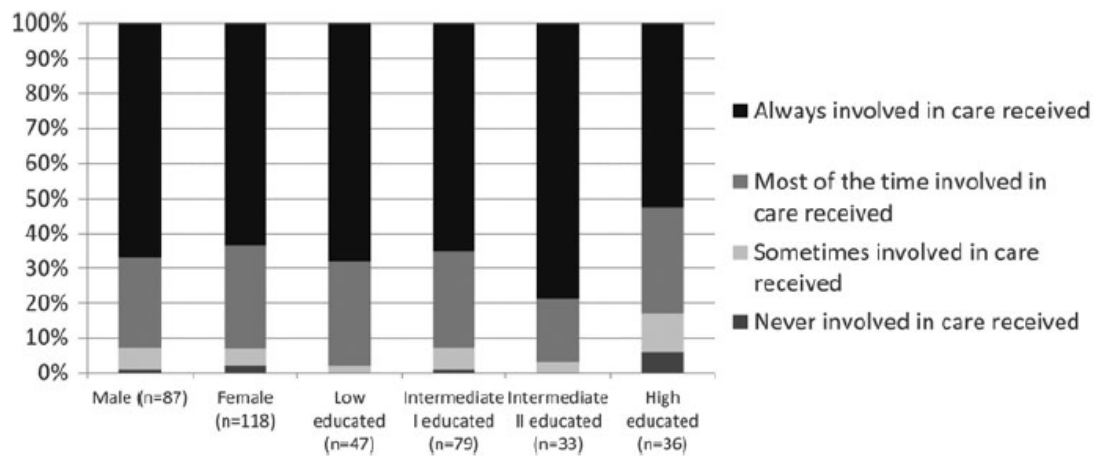

FIG. 2. Association between gender/education and feeling involved. From the 212 included participants, not all completed all measures. Hence, the number of participants per association varies.

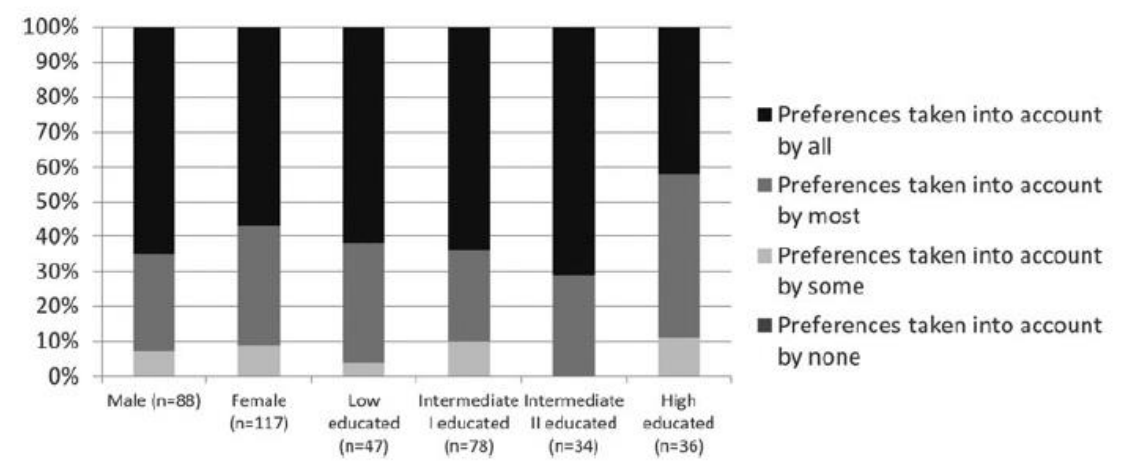

FIG. 3. Association between gender/education and feeling preferences taken into account. From the 212 included participants, not all completed all measures. Hence, the number of participants per association varies. 
Vliet, L.M. van, Veer, A.J.E. de, Raijmakers, N.J.H., Francke, A.L. Is information provision about benefits and risks of treatment options associated with receiving person-centered care: a survey among incurably ill cancer patients. Journal of Palliative Medicine: 2019, 7, p. 797-803

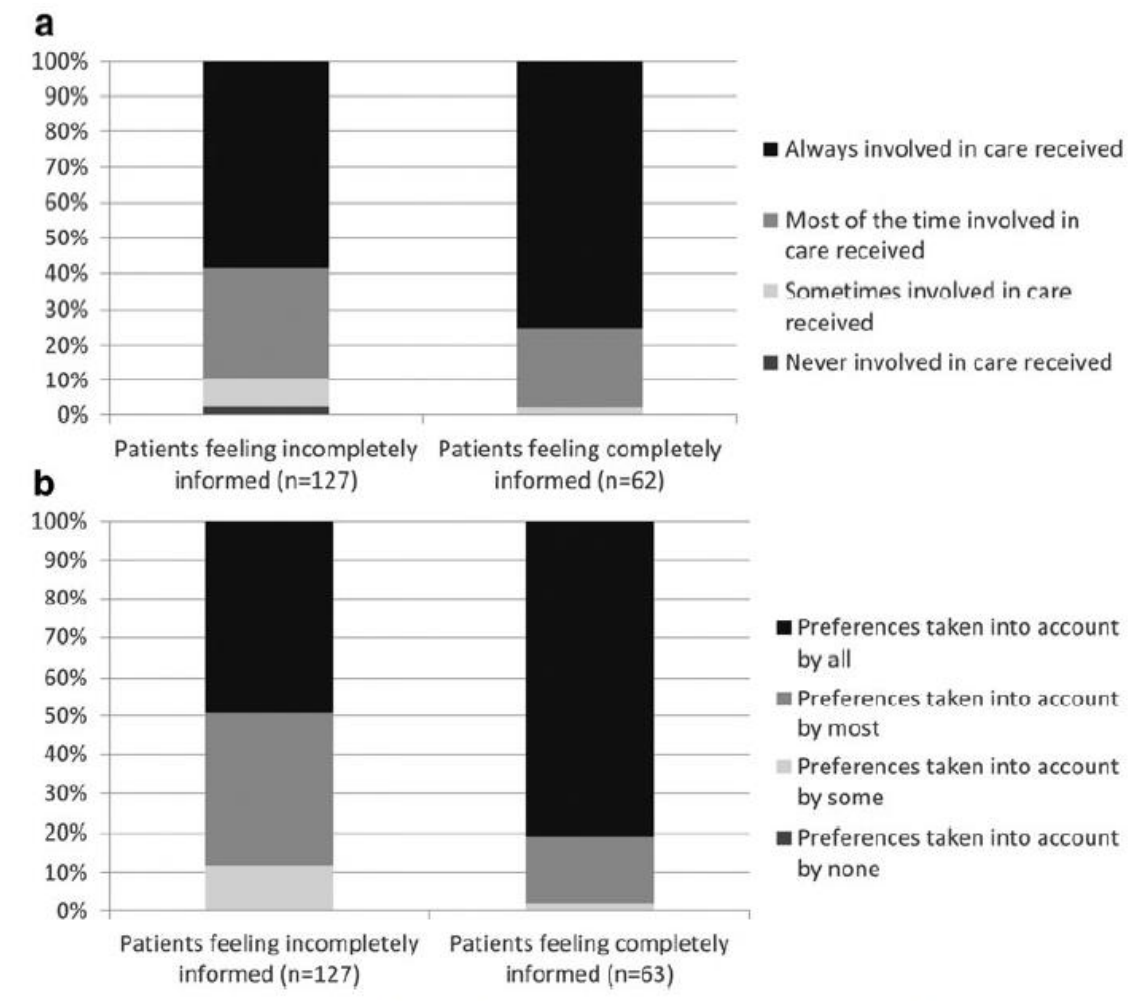

FIG. 4. (a) Association between feeling informed and feeling involved. From the 212 included participants, not all completed all measures. Hence, the number of participants per association varies. (b) Association between feeling informed and feeling preferences taken into account. From the 212 included participants, not all completed all measures. Hence, the number of participants per association varies. 